\title{
Upper urinary tract lipoma: A case report
}

\author{
Khalid Lmezguidi, MD; Fouad Hajji, MD;* Mohamed Sinaa, MD; ${ }^{\dagger}$ Abdellatif Janane, MD;* \\ Mohamed Ghadouane, MD; ${ }^{*}$ Ahmed Ameur, MD, ${ }^{*}$ Abderrahmane Albouzidi, MD; ${ }^{\dagger}$ Mohamed Abbar, MD*
}

*Department of Urology, Military Teaching Hospital-Rabat, Morocco; 'Department of Pathology, Military Teaching Hospital-Rabat, Moroccco

Cite as: Can Urol Assoc J 2015;9(9-10):E673-5. http://dx.doi.org/10.5489/cuai.2555 Published online September 9, 2015.

\section{Abstract}

Upper urinary tract (UUT) benign tumours are rare. We present a case of UUT lipoma in a 41-year-old man with left flank pain. A computed tomographic urography scan revealed an irregular thickening of the left renal collecting system wall extending from the upper calices to the renal pelvis. The diagnosis of UUT was made and the patient underwent a nephroureterectomy with bladder cuff excision, as standard treatment. However, macroscopic and histological examination revealed a lipomatous tumour with no sign of malignancy. To our knowledge this is the first reported case of its kind of a UUT managed first with a minimally invasive approach.

\section{Introduction}

Upper urinary tract (UUT) benign tumours are rare and originate from mesodermal tissue of the ureteral wall; ${ }^{1}$ its etiology is poorly understood. They are usually at the proximal ureter and renal pelvis. The main symptoms are caused by a urinary tract obstruction, with the most common symptoms being hematuria and flank pain. ${ }^{2}$ Preoperative radiological diagnosis is difficult and UUT are often discovered after surgical or endoscopic removal. To our knowledge, this is the first reported case of UUT.

\section{Case report}

A 41-year-old male with a history of stone disease treated with extracorporeal shock wave lithotripsy presented to the urology department with left flank pain, with no hematuria. Physical examination was unremarkable and did not reveal any abnormalities; laboratory values were within normal limits; his hemoglobin was $16.3 \mathrm{~g} / \mathrm{dL}$ and his serum creatinine level was $0.80 \mathrm{mg} / \mathrm{dL}$. The computed tomographic urography scan showed an irregular thickening of about $2 \mathrm{~cm}$ of the left renal collecting system wall extending from the upper calices to the renal pelvis, which revealed partial staghorn calculi and moderate hydonephrosis after moderately enhanced imaging with contrast injection (Fig. 1). The urine cytology did not reveal malignancy. A diagnosis of UUT tumour was made.

After informed consent was obtained by the patient, we performed a nephroureterectomy with bladder cuff excision by the conventional surgery technique with no perioperative complications. The patient recovered well and was discharged on postoperative day 5 .

A gross specimen examination revealed a $3.0 \times 2.2 \times 2.0$ $\mathrm{cm}$ fatty tumour in the calyceal cavities and extending to the renal pelvis and initial part of ureter (Fig. 2). Microscopic examination revealed a benign tumour proliferation composed of adipose tissue with no signs of malignancy (Fig. 3a, Fig. 3b).

\section{Discussion}

UUT benign lesions are rare and include endometriomas, fibromas, leiomyomas, granulomas, neurofibromas, hemangiomas, and lymphangiomas. ${ }^{1,2}$ Fibroepithelial polyps of the renal pelvis and ureter are the most common benign lesions affecting the UUT. ${ }^{3,4}$ To our knowledge, a UUT lipoma has never been reported.

Lipomas are benign lesions composed of adipose tissue typically found in the integument, gastrointestinal tract, or central nervous system. Eggener and colleagues reported a case of bladder lipoma revealed during evaluation for microscopic hematuria, but it was not clear whether the lipoma was the source of the hematuria. ${ }^{5}$ There are 3 reported cases of lipoma in the bladder. ${ }^{6-8}$ The main reported symptoms were hematuria, urgency, incontinence; some bladder lipomas also present as a retroperitoneal mass. ${ }^{9}$

Val-bernal and colleagues reported a case of incidental bladder lipoma during a cystoscopic examination after a nephroureterectomy for high-grade urothelial carcinoma of 


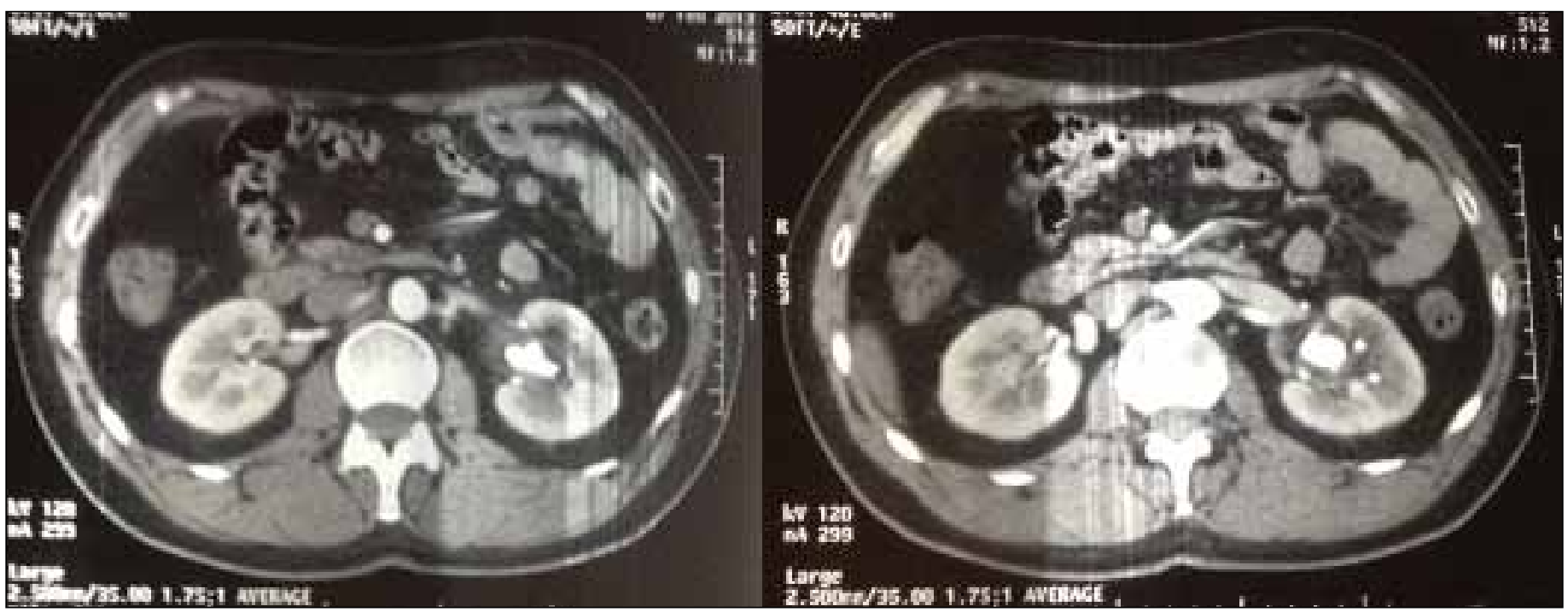

Fig. 1. Axial abdominal computed tomographic scan showing focal mass of renal pelvis complicated with a staghorn calculi and moderate hydronephrosis.

the renal pelvis; the lipoma was smooth and yellow with a submucosal polyp on the dome of the bladder wall. ${ }^{10}$ Less common symptoms include gross hematuria, ${ }^{11}$ gluteal pain, ${ }^{12}$ and irritative voiding symptoms, like nocturia. ${ }^{13}$

Urinary tract tumours can be classified as epithelial or mesenchymal. Primary epithelial tumours of the UUT are more common and are usually malignant, and mesodermal tumours of the UUT are rare lesions that are usually benign.

All patients should have biopsy-proven histologic confirmation before beginning definitive therapy.

The most common presenting signs and symptoms are hematuria and/or flank or abdominal pain. Urinary frequency, dysuria, and pyuria are less common. Cystoscopy is essential after an episode of gross hematuria to evaluate the bladder for urothelial tumours.

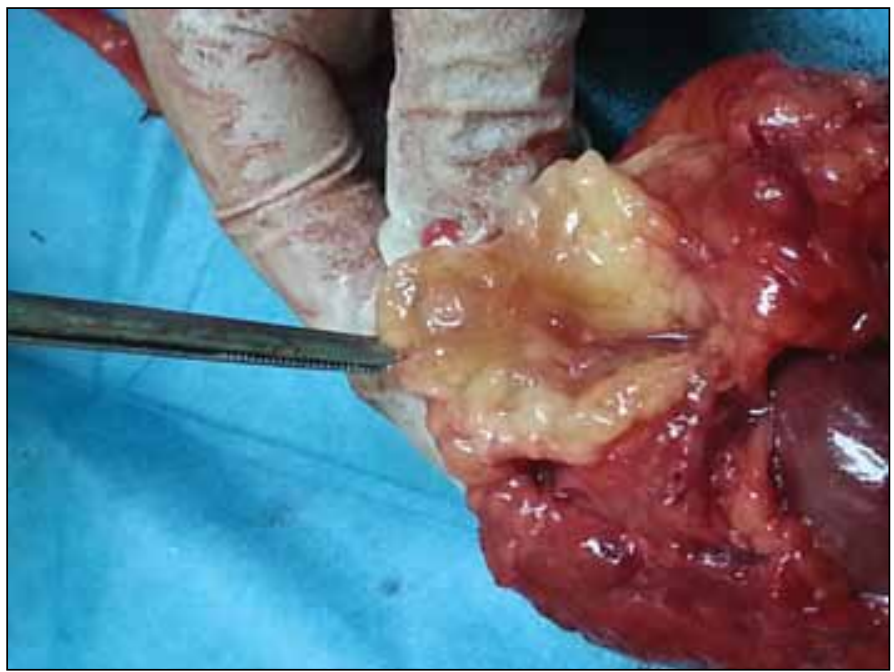

Fig. 2. Gross specimen of the left kidney showing lipomatous tumour of the renal pelvis.
With the advent of small-calibre ureteroscopes, endoscopic biopsy and resection of these tumours are becoming more popular. However, ureteroscopic resection can be difficult in patients with a long, polypoid lesion. This difficulty is often due to the inability to access the base of the stalk because of the pedunculated body of the lesion, which often can hang inferiorly for several centimeters and take up the entire lumen of the ureter. Visualization may also be poor and little working space is available, making it difficult to differentiate the ureteral wall from the lesion itself. It can be quite dangerous to start cutting in this setting, especially if the lesion cannot be retracted from the ureter. To completely remove the lesion, one must severe it its base and generously fulgurate the base to prevent recurrence. ${ }^{14,15}$

When malignancy is suspected or when an endoscopic approach is not practical, segmental resection of the ureter, a dismembered pyeloplasty, or a nephroureterectomy may be needed. This was the case in our patient.

\section{Conclusion}

Lipoma is a rare finding within the urinary tract. To our knowledge, UTT lipoma has never been reported as a benign lesion. We performed a flexible ureterorenoscopic exploration of UTT followed by a histologic examination of the biopsy specimen. This allowed us to accurately diagnosis the patient and tailor treatment.

Competing interests: The authors declare no competing financial or personal interests.

This paper has been peer-reviewed. 


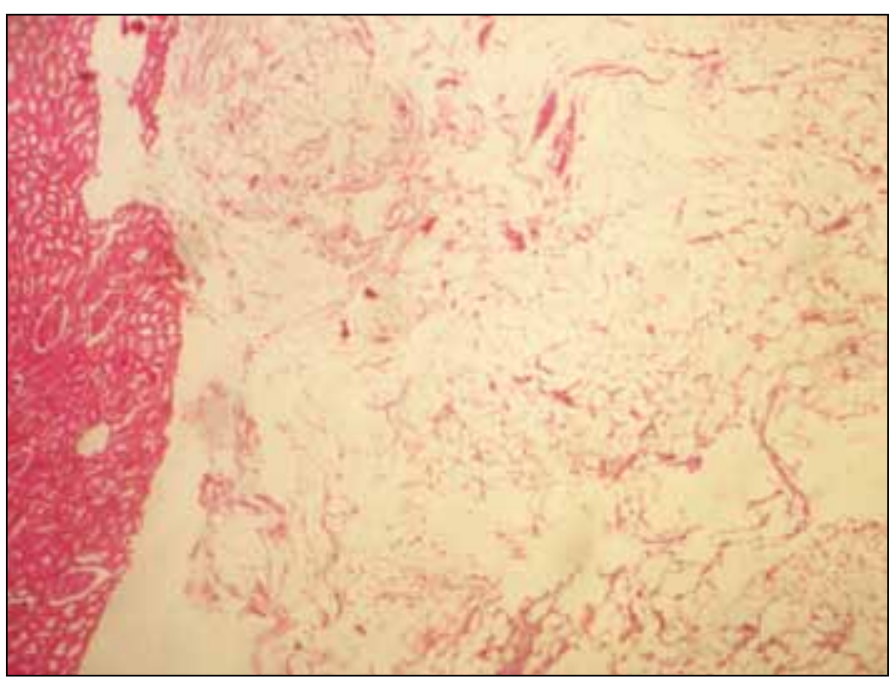

Fig. 3a. Hematoxylin \& eosin stain of upper urinary tract lipoma showing a benign proliferation of mature adipose tissue. There are no mitotic figures in specimen suggesting malignancy.

\section{References}

1. Kiel H, Ullich T, Roessler W, et al. Benign ureteral tumors: Four case reports and a review of the literature. Urol Int 1999;63:201-5. http://dx.doi.org/10.1159/000030448

2. Messing EM. Urothelial tumors of the urinary tract. In: Walsh PC, Retik AB, Vaughan ED Jr, et al (eds). Campbell's Urology. 8th ed. Philadelphia, PA: WB Saunders; 2002:2765-73.

3. Macksood MJ, Roth DR, Chang CH, et al .Benign fibroepithelial polyps as a cause of intermittent ureteropelvic junction obstruction in a child: A case report and review of the literature. J Urol 1985; 134:951-2.

4. Brady JD, Korman HJ, Civantos F, et al. Fibroepithelial polyp of the renal pelvis: Nephron-sparing surgery after falsepositive biopsy for transitional cell carcinoma. Urology 1997;49:460-4. http://dx.doi. org/10.1016/50090-4295(96)00484-0

5. Eggener SE, Hairston J, Rubenstein JN, et al. Bladder lipoma. J Urol 2001;166:1395. http://dx.doi. org/10.1016/S0022-5347(05)65784-9

6. Zajaczkowski T. Lipoma of the bladder [in Polish]. Pol Przegl Chir 1976;48:301.

7. Kracht H. Lipoma of the urinary bladder mucosa [in German]. Z Urol Nephrol 1966;59:269-72.

8. Alonso-Gorrea M, Tramoyeres Celma A, et al. Lipoma vesical: A proposito de un caso. Arch Esp Urol 1982;35:381.

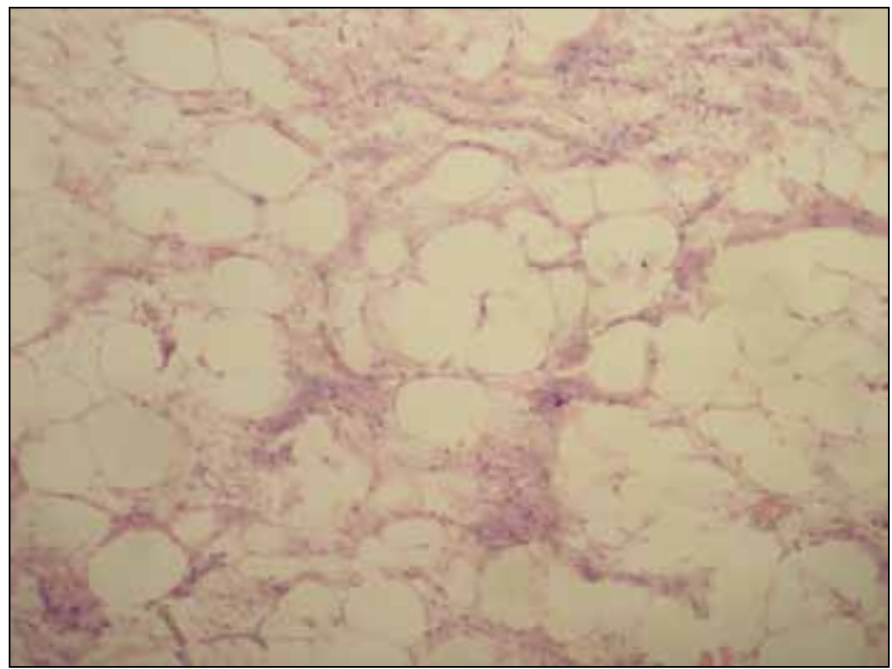

Fig. 3b. Higher power view of the specimen showing a thin tissue with univacuolar adipocytes without atypia (hematoxylin \& eosin $\times 25$ ).

9. Ukita $S$, Koshiyama M, Ohnaka M, et al. Retroperitoneal lipoma arising from the urinary bladder. Rare Tumors 2009; 1:e13.

10. Val-bernal JF, Azuteka A, Ballestero R, et al. Incidental bladder lipoma: A case report and review of the literature. Turk Patoloji Derg 2015;31:64-7.

11. Lang EK. Symptomatic bladder lipomas. J Urol 2005;174:313. http://dx.doi.org/10.1097/01. ju.0000167214.17437.cb

12. Brown C, Jones A. Bladder lipoma associated with urinary tract infection. ScientificWorldJournal 2008;8:573-4. http://dx.doi.org/10.1100/tsw.2008.91

13. Kunkle DA, Mydlo JH. Bladder wall lipoma in patient with irritative voiding symptoms. Urology 2005;66:653-4. http://dx.doi.org/10.1016/j.urology.2005.03.074

14. Bader MJ, Sroka R, Gratzke C, et al. Laser therapy for upper urinary tract transitional cell carcinoma: Indications and management. Eur Urol 2009;56:,65-71.

15. Borofsky MS, Shah 0. Advances in ureteroscopy. Urol Clin North Am 2013;40:67-78.

Correspondence: Dr. Khalid Lmezguidi, Department of Urology, Military Teaching Hospital-Rabat, Morocco; Imezguidikhalid@gmail.com 